\title{
Seminario Permanente \\ sobre Epistemología e Historia de la Matematica
}

\author{
Hernando Gutiérrez Hoyos \\ Programa de Matemáticas y Física
}

La mayor parte (por no hacer afirmaciones generalizantes) de los programas para formación de licenciados en Ciencias exactas naturales adolecen de asignaturas o actividades que "doten" a sus estudiantes de algunos elementos fundamentales para proveerse de una idea clara (la cual debe profundizarse) acerca de la naturaleza y el significado de los "objetos" sobre los cuales actúa la disciplina científica que constituye su campo básico de formación al igual que los métodos mediante los cuales se elaboran sus conceptos, se construyen sus conocimientos y la manera como se integran éstos (conceptos y conocimientos) para constituir un cuerpo de doctrina coherente que los identifique como ciencia.

En nuestra facultad de Educación y particularmente en el programa de matemáticas y física tal es la situación que se presenta. por tal motivo, y con la intención de "llenar"

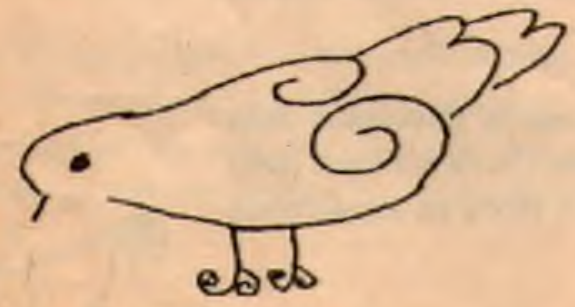

este vacío, nos hemos propuesto la tarea de estudiar la naturaleza del conocimiento matemático teniendo en cuenta (desde una perspectiva histórica y epistemológica) la formación y construcción tanto de los conceptos básicos como del conocimiento matemático en general al igual que la estructura organizativa de la misma.

Para asumir esta empresa se ha creado (por parte de un grupo de profesors y estudiantes adscritos al programa de licenciatura en Matemáticas) el "Seminario permanente sobre Epistemología e Historia de la Matemática".

La hemos asumido como seminario de acuerdo a la concepción alemana de Semillero, sembradío y lugar de recogimiento para el estudio y la investigación. Permanente en el sentido que no se cerrará su actividad con la primera cosecha sino que se buscará mantener el terreno siempre listo y abonado para quienes deseen cultivar y experimentar en él.

Tenemos la pretensiosa aspiración de que nuestro seminario se convierta en una institución sólida e independiente con identidad propia de tal forma que, al igual que los famosos seminarios alemanes del siglo $X I X$, se convierta en punto de referencia obligada para quienes en nuestro pais se ocupen o esten interesados en el estudio de esta faceta de las matemáticas. 